\title{
Comparison of two invitation-based methods for human papillomavirus (HPV) self-sampling with usual care among un- and under-screened Māori, Pacific and Asian women: study protocol for a randomised controlled community trial to examine the effect of self-sampling on participation in cervical-cancer screening
}

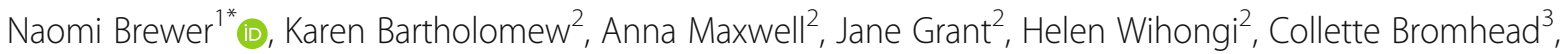
Nina Scott ${ }^{4}$, Sue Crengle ${ }^{5}$, Chris Cunningham ${ }^{6}$, Jeroen Douwes ${ }^{7}$ and John D. Potter ${ }^{7}$

\begin{abstract}
Background: Māori, Pacific and Asian women in New Zealand have lower cervical-cancer screening rates than European women, and there are persistent inequities in cervical cancer outcomes for Māori and Pacific women. Innovative ways to address access barriers are required. New Zealand is transitioning to screening with human papillomavirus (HPV) DNA testing, which could allow women themselves, rather than a clinician, to take the sample. Internationally, self-sampling has been found to increase screening participation rates. The aim of this open-label community-based randomised controlled trial is to investigate whether self-sampling increases screening participation among un- and under-screened Māori, Pacific and Asian women in New Zealand.

Methods/design: We aim to invite at least 3550 un- or under-screened ( $\geq 5$ years overdue) Māori, Pacific and Asian women (1050, 1250, 1250 respectively), aged 30-69 years, for screening. The three study arms are: usual care in which women are invited to attend a clinic for a standard clinician-collected cytology test; clinic-based selfsampling in which women are invited to take a self-sample at their usual general practice; and mail-out selfsampling in which women are mailed a kit and invited to take a self-sample at home. Women will be randomised 3:3:1 to the clinic and mail-out self-sampling groups, and usual care. There is also a nested sub-study in which nonresponding women in all allocation groups, when they subsequently present to the clinic for other reasons, are offered clinic or home-kit self-sampling. The primary outcome will be the proportion of women who participate (by taking a self-sample or cytology test).

(Continued on next page)
\end{abstract}

\footnotetext{
* Correspondence: N.Brewer@massey.ac.nz

${ }^{1}$ Centre for Public Health Research, College of Health, Massey University, PO

Box 756, Wellington 6140, New Zealand

Full list of author information is available at the end of the article
}

(c) The Author(s). 2019 Open Access This article is distributed under the terms of the Creative Commons Attribution 4.0 International License (http://creativecommons.org/licenses/by/4.0/), which permits unrestricted use, distribution, and reproduction in any medium, provided you give appropriate credit to the original author(s) and the source, provide a link to the Creative Commons license, and indicate if changes were made. The Creative Commons Public Domain Dedication waiver (http://creativecommons.org/publicdomain/zero/1.0/) applies to the data made available in this article, unless otherwise stated. 
(Continued from previous page)

Discussion: This trial is the first to evaluate the effectiveness of mailed self-sampling in New Zealand and will be one of the first internationally to evaluate the effectiveness of opportunistic in-clinic invitations for self-sampling. The trial will provide robust evidence on the impact on participation proportions from different invitation approaches for HPV self-sampling in New Zealand un- and under-screened Māori, Pacific and Asian women.

Trial registration: ANZCTR Identifier: ACTRN12618000367246 (date registered 12/3/2018) https://www.anzCtr.org. au/Trial/Registration/TrialReview.aspx?id=371741\&isReview=true; UTN: U1111-1189-0531.

Keywords: HPV DNA testing, Home-based, Clinic-based, Self-sample, Cervical screening, Participation

\section{Background}

The New Zealand National Cervical Screening Programme (NCSP) has been established for 28 years. Although cervical cancer incidence has declined in both Māori (the Indigenous people of New Zealand) and non-Māori, invasive disease persists, predominantly in women who are not screened or who are under-screened $[1,2]$. In 2014, cervical cancer registration (New Zealand Cancer Registry) was twice as high, and mortality rates three times as high in Māori women compared to non-Māori women [3]. Pacific women in New Zealand also have higher cervical cancer incidence [4].

Approximately $75 \%$ of cervical cancer cases among Pacific women in New Zealand have been found to occur in women who have not attended cervical screening [5]. Similarly, around 70\% of Asian women, and 59\% of Māori women diagnosed with cervical cancer were shown to have not been screened [5]. Cervical-cancer screening is recommended every 3 years in New Zealand. In June 2019, the three-year coverage proportion for 25-69year old women was $60.9 \%$ for Asians, $66.6 \%$ for Pacific, $66.8 \%$ for Māori, and 75.6\% for others (mostly European) [6].

There are many reasons for low participation in screening, which can be summarised as health system failure, attitudinal bias (racism), differential access, and quality of care [1, 2, 7-9]. Actions to reduce these barriers, including no-cost targeted testing ('free smears') and tailored practice-level data-matching to identify under-screened women to offer support, have been undertaken across the country. However, despite these measures, there has been little change in participation among Māori, Pacific and Asian women in the last decade [6]. Novel strategies are therefore required to change the landscape of cervical screening.

New Zealand is currently assessing policy options to inform a transition from traditional cervical screening by cytology (previously a 'pap smear', now liquid-based cytology (LBC)) to a human papillomavirus (HPV)-based programme. Because persistent cervical infection with oncogenic HPV causes virtually all cervical cancers, [10, 11] the World Health Organization [12] recommends primary HPV screening for early detection of cervical cancer. In high-resource settings, HPV testing for primary cervical cancer screening could: increase the efficiency of the existing programme; more effectively identify women at risk of precancerous changes; and, therefore, reduce incidence and mortality from cervical cancer [11]. In New Zealand, HPV testing of a clinician-collected sample for primary cervical cancer screening is predicted to give a $12-16 \%$ reduction in cervical cancer incidence and mortality [13].

New Zealand has an established HPV vaccination programme, now using Gardasil $^{\odot}$ 9, protecting young people of both sexes (aged 9 to 26 years) against HPV types $6,11,16,18,31,33,45,52$, and 58 [14]. However, in 2017, a large proportion (33\%) of young women were not vaccinated [15] and the earlier vaccine (Gardasil 4; used from 2008 to 2017), in particular, does not protect against all oncogenic HPV types.

Unlike cytology assessment, HPV testing is based on viral deoxyribonucleic acid (DNA) and does not require intact cells. Therefore, a less invasive method of sampling, aimed at simplifying the screening process and reducing barriers to programme participation, may be used, such as vaginal self-sampling [16]. Self-sampling approaches have consistently shown an improved participation rate in cervical screening, including among the least well-served women who are unscreened [16-21]. The iPAP trial in Australia, in which HPV self-sampling kits were mailed to under-screened women, demonstrated 20\% uptake compared with $6 \%$ for usual care [19]. HPV self-sampling has been included in the 2017 renewal of the Australian screening programme [22]. It has also been incorporated into the cervical screening programme in the Netherlands and has recently been introduced in the Capital Region of Denmark [23, 24]. In New Zealand, vaginal self-sampling is already used to test for sexually transmitted diseases [25] and has previously been suggested to be preferred by Māori women [26].

The accuracy of self-sampling in detecting high-grade precancerous cervical changes (cervical intraepithelial neoplasia grade two or higher; $\mathrm{CIN} 2+$ ) has been consistently shown to be similar to clinician-collected samples when tested for oncogenic HPVs using polymerase chain reaction (PCR) [18, 23, 27-29]. Most studies did not compare different sampling devices; however, no statistically significant difference was reported between a 
brush-based and a lavage-based device for CIN2+ and CIN3+ detection rates (when using a high-performing PCR DNA assay) and user comfort [30]. An inexpensive and low-tech device, the dry flocked swab, had the same accuracy for clinician-taken samples, when used with a dry tube (containing no preservative solution), as a cytobroom used with a wet tube (containing PreservCyt ${ }^{\circ}$ solution) in Australia [31].

Internationally, HPV self-sampling has been used with a range of invitation approaches, including in general practice clinics, [32] community-health-worker delivery [17] and by mail [31, 33]. A meta-analysis confirmed that: a range of delivery approaches are acceptable to under-screened women; there is improved participation among under-screened women; and the approach should be tailored to local populations [34].

The use of a novel HPV self-sampling technology in un- or under-screened Māori, Pacific and Asian women may improve participation as suggested by recent work in New Zealand [35, 36] and thus partially address the burden of cervical cancer in these populations. However, as recommended by Arbyn et al [27], a local trial is needed to assess feasibility, effectiveness, and cost-effectiveness before the introduction of a programme that includes self-sampling; this is the primary aim of the current study. In particular, we aim to evaluate the acceptability (assessed by participation (uptake)) of HPV self-sampling in the high-priority populations of un- and under-screened Māori, Pacific, and Asian women, with the ultimate goal of providing robust evidence for New Zealand policy decisions on cervical screening.

\section{Study objectives}

The primary study objectives are to determine: 1) the self-sampling participation proportion in Māori, Pacific and Asian women; 2) the follow-up proportion for oncogenic HPV-positive women, and; 3) the prevalence of oncogenic HPV positivity (including genotype) and the associated colposcopic findings.

The secondary objectives are to: 1) determine the level of support needed to achieve at least $90 \%$ follow-up of oncogenic HPV-positive women to attend a primarycare smear-taker or colposcopy; 2) provide policy relevant findings for New Zealand to facilitate future implementation of national self-sampling within the next 5 years; 3) determine some acceptability issues, including: what preferences women have for invitation, sample return, and follow-up methods; whether the level of information in the printed material is appropriate and acceptable to Māori, Pacific, and Asian women; and whether further localisation or refinement is required; and 4) ultimately improve equitable health outcomes for Māori, Asian, and Pacific women in New Zealand.

\section{Methods/design}

This is an open-label, three-arm, community-based, randomised controlled trial, with a nested sub-study (Fig. 1). We will invite a minimum of 3550 un- or underscreened (no screening recorded for the last 5 years, in accordance with the NCSP guidelines [37]) women. This group of women are least served by, and not engaged in, the current screening programme. The women will be identified through a routinely available national datamatch process between Primary Health Organisations (PHOs; organisations responsible for primary care) and the NCSP, where the screening status of enrolled women is updated monthly. Participants will be Māori, Pacific or Asian women (1050, 1250, 1250 respectively), as identified by the PHO enrolment register, invited through the women's usual primary care provider (in partnership with the research team) in the Auckland area (Waitematā District Health Board (DHB) and Auckland DHB). Ethnicity in New Zealand is self-identified as part of PHO enrolment; women identifying with multiple ethnicities are prioritised according to the New Zealand ethnicity standard for the health sector [38].

Women will be individually randomised 3:3:1 to the study arms: clinic-based self-sampling in which women are invited to take a self-sample at their usual general practice (GP); mail-out self-sampling in which women are mailed a kit and invited to take a self-sample at home; and usual care in which women are invited to attend a clinic for a standard cytology sample (attendance assessed through the NCSP-Register and GP records). We aim to randomise approximately equal numbers of women from each ethnic group to each of the study arms. There is also a nested "opportunistic" sub-study at most clinics, where women who have not responded within 3 months to their study invitation are offered, at any subsequent visit to their clinic (as suggested in Arbyn et al [27] and Lim and Sasieni [39]), either selfsampling in the clinic or the option of having a sampling kit mailed to their home. This sub-study will enable us to describe policy-relevant findings including those that inform the practical implementation of an opportunistic offer of HPV self-sampling in a clinic situation.

An overview of the schedule of enrolment, interventions, and assessments is provided in Table 1.

\section{Exclusions}

Exclusions as per the NCSP guidelines [37] will include women who: 1) have had a benign total hysterectomy; 2) have previously had or currently have cervical cancer; or 3) are symptomatic (abnormal bleeding, pelvic pain, or symptoms of a sexually transmitted infection; these women are referred for appropriate care). In addition, women will be excluded if they: 1 ) have previously had a high-grade lesion and have not attended for colposcopy 

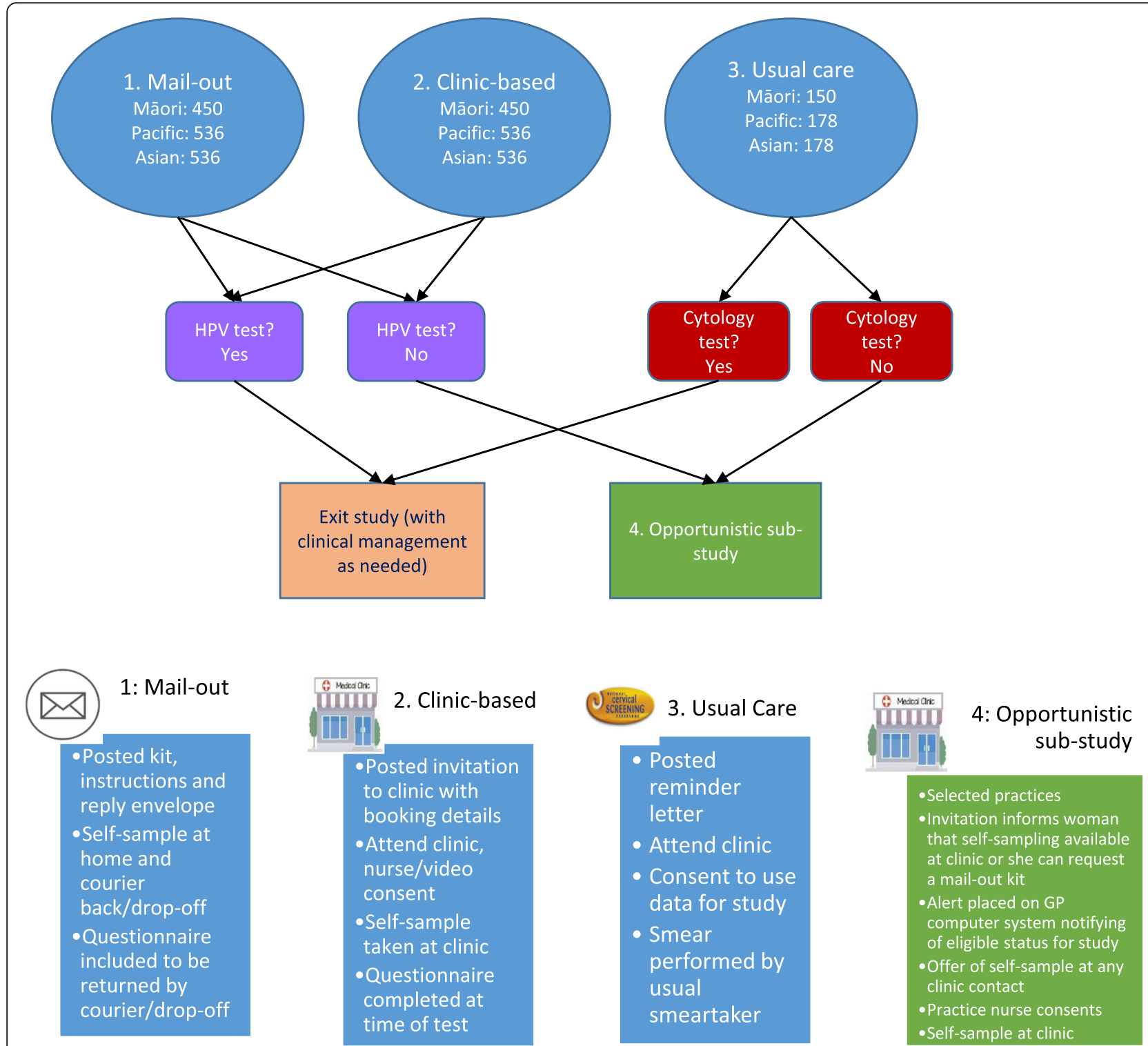

Fig. 1 Study design overview

(remaining at high clinical risk); 2) have previously had a high-grade lesion and have not completed follow-up according to NCSP guidelines [37]; 3) are currently pregnant; 4) are not eligible for New Zealand health services; 5 ) have not attended the specific clinic in the last 3 years; and 6) other clinical reason (e.g. terminal illness).

\section{Interventions}

\section{Invitation}

Although cervical screening is recommended for all NZ women from age 20-69 [37] (the NCSP is increasing the screening start age to 25 years in 2019 [40]), the prevalence of HPV infections in women $<30$ years is high and most infections clear without causing cervical abnormalities; this reduces the specificity of HPV testing [37, 41].
The age range for our study is therefore $30-69$ years: to minimise unnecessary colposcopy procedures in younger women; to avoid self-sampling being the first contact for cervical screening among women who might otherwise choose current screening programme; and to maintain the specificity of the HPV testing.

All women who meet the study inclusion criteria will be sent a tailored pre-invite letter briefly explaining the study and informing them that, unless they request not to receive an invitation, they will soon be sent: 1) an invitation for cytology (usual care); 2) a self-sampling kit (mail-out); or 3) an invitation to take a self-sample at their GP clinic (clinic-based). Two weeks after the preinvite letters have been sent, women will be randomised (excluding any who have indicated that they do not wish 
Table 1 Overview of the schedule of enrolment, interventions, and assessments. Participation means providing a sample and optionally completing the questionnaire

\begin{tabular}{|c|c|c|c|c|c|c|}
\hline \multirow[b]{3}{*}{ TIMEPOINT** } & \multicolumn{6}{|c|}{ STUDY PERIOD } \\
\hline & \multirow[b]{2}{*}{$\begin{array}{c}\text { Pre- } \\
\text { intervention } \\
\text { (baseline) }\end{array}$} & \multirow[b]{2}{*}{ Week 2} & \multicolumn{3}{|c|}{ Post-allocation } & \multirow{2}{*}{$\begin{array}{l}\text { Close-out } \\
\text { Month } 18\end{array}$} \\
\hline & & & Week 4 & Month 3 & Month 9 & \\
\hline \multirow{6}{*}{$\begin{array}{l}\text { ENROLMENT: } \\
\text { Eligibility screen } \\
\text { Pre-invite letter with } \\
\text { option to opt-out } \\
\text { Randomisation } \\
\text { Invitation letter sent } \\
\text { Informed consent }\end{array}$} & & & & & & \\
\hline & $\mathrm{x}$ & & & & & \\
\hline & $\mathrm{x}$ & & & & & \\
\hline & & $\mathrm{X}$ & & & & \\
\hline & & $x$ & & & & \\
\hline & & $\hookleftarrow$ & & & $\rightarrow$ & \\
\hline \multicolumn{7}{|l|}{ INTERVENTIONS: } \\
\hline \multirow{2}{*}{\multicolumn{7}{|c|}{$\begin{array}{r}\text { Mail-out group } \\
\text { sampling kit mailed } \\
\text { Mail-out group } \\
\text { participation }\end{array}$}} \\
\hline & & & & & & \\
\hline \multicolumn{7}{|l|}{$\begin{array}{r}\text { Clinic-based group } \\
\text { participation }\end{array}$} \\
\hline $\begin{array}{r}\text { Usual care group } \\
\text { participation }\end{array}$ & & & & & & \\
\hline \multirow{4}{*}{$\begin{array}{r}\text { Text reminder sent } \\
\text { Censor participation } \\
\text { response } \\
\text { Text invitation to } \\
\text { opportunistic group } \\
\text { sent } \\
\text { Opportunistic group } \\
\text { participation }\end{array}$} & & & $x$ & & & \\
\hline & & & & $x$ & & \\
\hline & & & & $x$ & & \\
\hline & & & & & & \\
\hline \multicolumn{7}{|l|}{ ASSESSMENTS: } \\
\hline \multicolumn{7}{|l|}{ HPV testing } \\
\hline \multicolumn{7}{|l|}{ Cytology testing } \\
\hline $\begin{array}{l}\text { Collection of cytology } \\
\text { and histology results }\end{array}$ & & & & & & $\mathrm{X}$ \\
\hline
\end{tabular}

to receive an invitation), using a computer-generated sequence, to one of the study arms and sent an invitation.

\section{Consent and sampling kit}

Participating women in the usual-care arm of the study who attend will be consented by their usual smear-taker and a cytology sample taken.

Participating women in the self-sampling arms of the study will be asked to take a low-vaginal sample with a FLOQSwab $^{\text {TM }}$ (Copan Italia, Brescia, Italy; similar to those now widely used for self-sampling for other sexually transmitted infections) and to put the swab into a $12 \mathrm{~mL}$ dry tube (Sarstedt AG \& Co. KG, Germany).

The clinic-based self-sampling group will receive an invitation letter and participant information brochure via their primary-care provider. The women will also be directed to a webpage [42] with translated study documents and study video clips (with subtitles in Te Reo Māori, Tongan, Samoan, Korean, and Simplified
Chinese). They will be invited to: 1) attend the clinic, give informed consent, and take the sample (e.g. in the clinic bathroom); 2) return the kit to the practice nurse; and 3) complete a questionnaire on: i) their experience; ii) the acceptability of the self-sampling process; and iii) their preferences.

The mail-out self-sampling group will receive an invitation letter and the self-sampling kit and information package in the mail. The self-sampling kit and information package will contain: 1) the participant information brochure; 2) an informed consent document; 3) a laboratory request form; 4) a questionnaire regarding acceptability; 5) a swab and tube; 6) instructions on how to take the sample and to return it as soon as possible; and 7) a return, free, pre-addressed courier bag. They will also be directed to the webpage with translated study documents and the study video clips.

Once samples are collected, the tubes will be placed in a biohazard bag together with the consent/laboratory test request form, and placed in the courier pick-up area for 
samples taken at a clinic or into the courier bag for samples taken at home. Women may also choose to drop their sample back at their general practice clinic or direct to the laboratory. Samples will be stored and transported at room temperature. The number of days between collection of the sample and receipt by the laboratory will be recorded.

Four weeks after the invitation letters have been sent, non-responding women will be sent a reminder text message.

\section{Opportunistic sub-study invitation}

In a subset of general practices, study subjects who have not participated in the study 3 months after invitation will have an alert placed on the clinic practice-management system stating that they are eligible for the sub-study. They will also be sent a letter or text informing them that they are now able to self-sample at their clinic or request that a self-sampling kit be mailed to them, both for a limited period of time. At any clinic-visit over the subsequent 6 months, the alert will notify the clinic to offer selfsampling and the study subjects will be able to take the test at the clinic and complete the questionnaire. Clinic staff will be trained to consent women to the study and to manage results. The same outcomes will be measured in the sub-study as in the main study.

\section{Study materials}

With permission from authors of the iPAP trial, iPAP materials for women have been adapted to local language usage and cultural context ('localised') and redeveloped into a participant information brochure, consent materials, results information and laboratory forms as part of the New Zealand feasibility study [43]. The localisation included ensuring that findings from qualitative studies for iPAP [44] (e.g. addressing women's concerns of not collecting the sample correctly and highlighting that HPV testing is not a test of spouse/partner fidelity) were addressed.

\section{Questionnaire}

Based on the Australian iPap study-responders post-test questionnaire [45], a questionnaire regarding acceptability has also been developed and localised. The questionnaire includes information on the women's experience with the self-sampling procedure (including pain, discomfort, and privacy or embarrassment concerns); aspects of feasibility (such as ease of use, confidence in the test, and confidence of correctly taking the sample themselves compared with confidence of a health-professional correctly taking the sample); practical issues (such as ease of getting an appointment with a smear-taker); the women's preference for specimen-collection technique (self-sampling or a clinician-collected sample); their willingness to participate in self-sampling-based screening in the future; whether they viewed the study videos; and demographic details (such as level of education and socioeconomic position). The questionnaire also asks whether the instructions for the self-sampling technique were clear, to enable us to ensure that any instructions in the future are clear and acceptable to Māori, Pacific, and Asian women.

A separate, short questionnaire has been developed and will be administered, with verbal consent, by telephone - to a random sample of approximately 24 nonresponding women to examine their reasons for nonparticipation.

\section{Laboratory testing \\ Cytology testing}

Cytology testing will be carried out in accordance with NCSP standards [46].

\section{HPV testing}

All samples will be tested for the presence of oncogenic HPV DNA using the clinically validated cobas 4800 HPV assay [29, 47] (Roche Molecular Systems, Pleasanton, California, USA) at a single accredited laboratory. The cobas 4800 HPV assay is approved by the US FDA for primary HPV screening (other HPV DNA assays are approved for use in conjunction with cytology) [48]; fulfils the New Zealand-specific criteria for HPV testing [46]; and has been selected by the Netherlands for primary HPV testing [49]. This assay specifically detects HPV types 16 and 18, as well as 12 other oncogenic HPV types as a group [48]. The protocol for testing selftaken swabs on the cobas HPV test is not validated by the manufacturer (Roche), but was validated by an Australian study [31]. On receipt in the laboratory, samples will be irrigated in $4 \mathrm{~mL}$ of PreservCyt buffer, and vortexed for at least $30 \mathrm{~s}$ prior to decapping and loading in swab-sample carriers on the cobas 4800 . The cobas HPV test is then run according to the manufacturer's instructions. All failed and invalid samples will be recorded and a repeat sample requested.

\section{Future laboratory analyses}

With women's consent, we will freeze an aliquot of each self-test sample that had a positive test result for oncogenic HPV for future HPV 'other' type differentiation. No analysis of human tissue or human genetic analysis will be performed; the only potential future analysis will be of specific viral DNA related to understanding the prevalence of non16/18 types of oncogenic HPV's in the study population.

\section{Results management}

\section{Negative results management}

Negative results (i.e., samples showing no evidence of HPV) will be provided to women by letter, text message, 
or telephone call by the usual primary-care provider and they will be advised to return for a routine cervical screen at the appropriate clinical interval, as specified by the NCSP guidelines and an amended approach to the proposed HPV primary-screening algorithm, with agreement from the NCSP (3 year recall interval) [37].

\section{Cytology results management}

Women with inadequate or abnormal cytology (taken in usual care or as follow-up to a HPV 'other' result) will be followed-up according to the NCSP guidelines [37] by the requesting smear-taker.

\section{Oncogenic HPV results management}

Positive HPV results will be managed as per the current NCSP guidelines, with adjustments in accordance with NCSP clinical advice [50]. The majority of women will be informed of their test results over the phone, with a few being informed in person by their usual primarycare provider. Women who test HPV16/18 positive will be referred directly to colposcopy. In order to avoid an additional cytology test (since this is potentially a barrier to follow-up), 'blind' colposcopy will be conducted (i.e. colposcopy will be performed before cytology, with the cytology sample being taken at colposcopy). Women who test positive for the pool of 12 other oncogenic HPV types will be triaged (at no cost to the woman) with a clinician-conducted cervical-cytology test (i.e. the current standard screening test); however, if the woman declines cytology, she may be offered a colposcopy to ensure safe follow-up. In accordance with NCSP guidelines, [50] women who return cell changes greater than low-grade on cytology will also be referred to colposcopy and women whose cytology is low-grade or less will be referred for management by their usual primary-care provider team for a repeat cytology test after 1 year.

\section{Clinical follow-up}

To ensure clinical safety, the return-of-results primarycare clinician will have 10 days to contact the woman, during which they will explain the results and, in the case of HPV16/18-positive women, make a referral for colposcopy. In the case of women who have a positive test result for other oncogenic HPV types, the return-ofresults clinician will make an appointment to take a cytology sample. The study nurse will monitor positive results and provide a failsafe follow-up process: if the participant is not informed in the 10-day timeframe, the study research nurse will work with the GP and provide, or refer for, support-to-service to ensure that women are notified and offered support to attend appropriate follow-up or provide the follow-up themselves. Nonattenders for abnormal cytology results will be followed up until the end of the study by the study nurse and then by their usual primary-care providers.

All screening elements will be free to participants. We will partner with local primary-care, support-to-service providers, Māori/Pacific/Asian Providers, and DHB colposcopy services to design and test appropriate supportto-service strategies to ensure that the majority of women who test positive for oncogenic HPV will be seen in clinic. This support will be tailored to meet women's needs and may include transport, childcare, and visitattendance support.

\section{Collection of clinical results}

We will obtain the results of any subsequent cervical cytology, colposcopy, and histology from the NCSPRegister or GPs, ISPs, Māori/Pacific/Asian Providers, and DHB colposcopy services in order to determine prevalence of cervical abnormalities.

\section{Data entry, management and security}

A bespoke secure online database has been created to manage details of responding and non-responding participants. Access databases will be developed for data entry from the study questionnaires. Any specimen taken for screening as part of the study is reported to the NCSP-Register by direct laboratory notification.

An internal data safety monitoring committee has been established (public-health physician; molecular HPV expert; general practitioner; colposcopist; nurse smear-taker; research nurse; epidemiologist) to assess and evaluate any clinical concerns or serious adverse events occurring in the study.

\section{Statistical analysis}

The main analyses will focus on the primary outcome of the study: participation, i.e. the proportion of women who provide a self-sample compared with the proportion who attend for cytology, stratified by ethnicity. These will initially be assessed simply by comparing (with Chisquare tests) the proportions who participated in each group; this will be followed by a mixed model multiple logistic regression analysis to adjust for potential confounders (e.g. age, ethnicity, screening history, socioeconomic status) and to assess which factors (in addition to the intervention) affect participation. The same analyses will be repeated separately for both un- and underscreened women, providing important information on whether screening history affects participation.

We will also analyse the prevalence of oncogenic HPV types in participating women in the selfsampling groups, and the prevalence of cervical abnormalities in participating women in the cytology group. Prevalence odds ratios [51] will be calculated 
using logistic regression and compared across ethnicities, adjusting for age.

Secondary analyses will assess the association between acceptance of self-sampling and demographic and other factors. For comparisons across ethnicity and screening-history (un- and under-screened) groups, logistic regression will be used, adjusting for age and other potential confounding variables. Time for return of sample will be calculated for self-sampling groups as a policy-relevant indicator of courier reliability; laboratory turnaround time and proportion of unsatisfactory samples will be monitored.

Experience of the test, enablers/barriers of screening, and factors associated with screening preferences will be described for each group (mail-out or clinic-based), by ethnicity and demographic factors. Standard descriptive statistical methods will be used. T-tests and Chisquare tests will be used to assess statistical significance. Multiple linear or logistic regression (as appropriate) will be used to compare these responses between the two groups (mail-out or clinic-based), adjusting for potential confounders.

\section{Sample size}

We aim to invite a minimum of 3550 un- or underscreened ( $\geq 5$ years overdue) Mãori, Pacific and Asian women (1050, 1250, 1250 respectively) for screening. The invitation numbers are pragmatically based on the number of eligible women in the region and study resources. With 450 Māori women invited in both the clinic and mail-out self-sampling groups we will have $>95 \%$ power to detect a $10 \%$ difference in uptake between the groups (e.g., 15\% uptake in the clinic group and $25 \%$ in the mail-out group). With 450 Māori women invited in the clinic self-sampling group and 150 Māori women invited in the usual care group we will have $>85 \%$ power to detect a $10 \%$ difference in uptake between the groups (e.g., 15\% uptake in the clinic group and $5 \%$ in the usual care group).

\section{Ethical and cultural considerations}

The study has been approved by the New Zealand Northern B Health and Disability Ethics Committee (HDEC) (reference: 17/NTB/120). The New Zealand Ministry of Health (including the National Kaitiaki Group) and the participating DHBs, PHOs, and primarycare clinics have all given approval for the use of data to identify and contact eligible women.

There are a range of ethical and cultural issues in this study. The issues include informed consent, privacy and confidentially, language barriers (especially for Pacific and Asian women), health literacy and awareness of screening, sampling and storage of tissue, data ownership, and that for some women (especially Māori women) the genital area is considered tapu (sacred/ forbidden/taboo). Whakamā (embarrassment/reticence/ shyness) may be an issue for some women in this study, and appropriate ways to approach women will be codesigned with each provider; a range of strategies are likely to be required. There is also the issue of potential stigmatisation (e.g. a deficit focus for un-screened/ under-screened women); however, this study seeks a strength-based approach of enabling women to access a novel technology to enhance their wellbeing. Our research group includes substantial research expertise with Māori health, Māori research methodology, and research with women, screening, and in cervical screening specifically. The study has an advisory group structure for each of the study populations: Mãori, Pacific and Asian.

\section{Discussion}

The success of cervical-cancer screening in New Zealand is limited by incomplete participation, particularly amongst Māori, Pacific and Asian women. More than half of the invasive cervical cancer cases among these populations occur in those who have not attended cervical screening [5]. Improving participation rates and reducing outcome inequities are priorities for New Zealand's health system. The longstanding nature of these problems shows that new strategies are needed. HPV self-sampling may improve the participation rates in groups of women who are underserved by current screening programmes that require a clinician-collected sample [34]. However, it is important to assess the acceptability and optimal invitation approaches for selfsampling in New Zealand in order to provide the country-specific evidence needed to inform policy. The current trial will provide robust evidence on whether HPV self-sampling could be used to increase cervical screening participation rates in un- and under-screened Māori, Pacific, and Asian women. This trial is the first to evaluate the effectiveness of mailed self-sampling for cervical-cancer screening in New Zealand, and one of the first internationally to evaluate the effectiveness of opportunistic in-clinic invitations for self-sampling.

\footnotetext{
Abbreviations

ANZCTR: Australian and New Zealand Clinical Trials Registry; ASC-H: Atypical squamous cells - cannot exclude high-grade squamous intra-epithelial lesion; ASC-US: Atypical squamous cells of undetermined significance;

CIN2 +: Cervical intraepithelial neoplasia grade two or higher; CIN3+: Cervical intraepithelial neoplasia grade three or higher; DHB: District Health Board; DNA: Deoxyribonucleic acid; GP: General Practice; HDEC: Health and Disability Ethics Committee; HPV: Human papillomavirus; HSIL: High-grade squamous intra-epithelial lesion; ISP: Independent Service Providers; LBC: Liquid-based cytology; LSIL: Low-grade squamous intra-epithelial lesion; NCSP: New Zealand National Cervical Screening Programme; PCR: Polymerase chain reaction; PHO: Primary Health Organisation; US FDA: United States Food and Drug Administration
} 


\section{Acknowledgements}

We thank the healthcare professionals (primary care and colposcopy clinicians) and participating women who are making this trial possible. We also thank the Australian IPAP investigators, particularly Marion Saville, for their advice and for allowing the localisation to New Zealand of their study materials.

\section{Authors' contributions}

$\mathrm{NB}, \mathrm{KB}, \mathrm{AM}, \mathrm{JG}, \mathrm{HW}, \mathrm{CB}, \mathrm{JD}$ and JP contributed to the study design and protocol writing. NB drafted the manuscript. NB and AM are coordinating the trial. $\mathrm{KB}$ and $\mathrm{JG}$ are providing clinical management and oversight of the trial. HW, NS, SC and CC are providing cultural-safety oversight of the trial. CB is managing the testing and reporting of HPV genotyping results and quality assurance. NB, KB, AM, JG, HW, CB, JD and JP are contributing to study conduct. JD and JP have overall responsibility for the conduct of the study. $J D$ and JP critically read and revised the first draft of the manuscript. All authors critically read and revised the second draft of the manuscript, and approved together the final version of the manuscript.

\section{Authors' information}

Not applicable.

\section{Funding}

This research is supported by the Health Research Council of New Zealand (grant 16/405), who peer-reviewed the study protocol. The funding body played no role in the design of the study, and is playing no role in the collection, analysis, and interpretation of data or in writing the manuscript.

\section{Availability of data and materials}

Anonymized data and biological samples will be collected during the trial and used only for the analysis declared in the study protocol. The availability of the data that will be collected as part of this study is being confirmed.

\section{Ethics approval and consent to participate}

This study has been granted ethics approval from the New Zealand Northern B Health and Disability Ethics Committee (reference: 17/NTB/120). Participants will give written informed consent, or consent will be assumed when a sample is received without a consent form.

\section{Consent for publication}

Not applicable.

\section{Competing interests}

NB has been employed by a different university to assist with unrelated research funded by Janssen Cilag Ltd. CB has previously received education grants from Roche Diagnostics NZ and research funding from Hologic Australia. Roche Diagnostics NZ provided swabs and subsidised cobas HPV test kits for a pilot study carried out by NB, CB, JD and JP.

\section{Author details}

'Centre for Public Health Research, College of Health, Massey University, PO Box 756, Wellington 6140, New Zealand. ${ }^{2}$ Waitematā District Health Board (DHB) and Auckland DHB, Private Bag 93-503, Takapuna, Auckland 0740, New Zealand. ${ }^{3}$ School of Health Sciences, Massey University, Wellington, New Zealand. ${ }^{4}$ University of Auckland, Waikato District Health Board, Hamilton, New Zealand. ${ }^{5}$ Department of Preventive and Social Medicine, University of Otago, Dunedin, New Zealand. ${ }^{6}$ Research Centre for Māori Health and Development, Massey University, Wellington, New Zealand. ${ }^{7}$ Centre for Public Health Research, Massey University, Wellington, New Zealand.

\section{Received: 10 October 2019 Accepted: 22 November 2019}

Published online: 09 December 2019

\section{References}

1. Robson B, Purdie G, Cormack D. Unequal Impact II: Māori and non-Māori Cancer statistics by deprivation and rural-urban status 2002-2006. Wellington: Te Rōpū Rangahau Hauora a Eru Pōmare, University of Otago; 2010.

2. Sadler L, Priest P, Peters J, Crengle S, Jackson R. The New Zealand cervical Cancer audit report. Whakamātau mate Pukupuku Taiawa o Aotearoa. Screening of women with cervical Cancer, 2000-2002. Ministry of Health: Wellington; 2004.
3. Smith M, Rumlee L, Canfell K. National Cervical Screening Programme Annual Report 2015. National Screening Unit: Wellington; 2018.

4. Ministry of Health. 'Ala Mo'ui: pathways to Pacific health and wellbeing 2010-2014. Wellington: Ministry of Health; 2010.

5. Brewer N, Pearce N, Jeffreys M, Borman B, Ellison-Loschmann L. Does screening history explain the ethnic differences in stage at diagnosis of cervical cancer in New Zealand? Int J Epidemiol. 2010;39(1):156-65.

6. National Cervical Screening Programme Coverage Report. https:// minhealthnz.shinyapps.io/nsu-ncsp-coverage/. Accessed 13 Aug 2019.

7. Cartwright S. The report of the Committee of Inquiry into allegations concerning the treatment of cervical Cancer at National Women's hospital and into other related matters. Auckland: Government Printing Office; 1988.

8. Foliaki S, Matheson A. Barriers to cervical screening among Pacific women in a New Zealand urban population. Asian Pac J Cancer Prev. 2015;16(4):1565-70.

9. Wihongi $\mathrm{H}$. An exploration of Māori health promotion within the National Cervical Screening Programme: a discussion document. Health Funding Authority: Auckland; 2000.

10. Walboomers JM, Jacobs MV, Manos MM, Bosch FX, Kummer JA, Shah KV, Snijders PJ. Human papillomavirus is a necessary cause of invasive cervical cancer worldwide. J Pathol. 1999;189(1):12-9.

11. Castle PE. The new era of primary HPV screening for prevention of invasive cervical cancer. Cancer Forum. 2014;38(3):209-14.

12. World Health Organization. Guidelines for screening and treatment of precancerous lesions for cervical cancer prevention. Geneva: World Health Organization Press; 2013.

13. Lew JB, Simms K, Smith M, Lewis $H$, Neal H, Canfell K. Effectiveness modelling and economic evaluation of primary HPV screening for cervical cancer prevention in New Zealand. PLoS One. 2016;11(5):E0151619.

14. HPV vaccine. http//www.health.govt.nz/our-work/preventative-health-wellness/ immunisation/hpv-immunisation-programme/hpv-vaccine. Accessed 30 Jan 2017.

15. Ministry of Health. HPV immunisation coverage by ethnicity and eligible birth cohort. http://www.health.govt.nz/our-work/preventative-health-wellness/ immunisation/hpv-immunisation-programme. Accessed 12 Sept 2019.

16. Camilloni L, Ferroni E, Cendales B, Pezzarossi A, Furnari G, Borgia P, Guasticchi G, Rossi P. Methods to increase participation Working Group. Methods to increase participation in organised screening programs: a systematic review. BMC Public Health. 2013;13(1):464.

17. Arrossi S, Thouyaret L, Herrero R, Campanera A, Magdaleno A, Cuberli M, Barletta P, Laudi R, Orellana L. Effect of self-collection of HPV DNA offered by community health workers at home visits on uptake of screening for cervical cancer (the EMA study): a population-based cluster-randomised trial. Lancet Glob Health. 2015;3(2):e85-94.

18. Snijders PJF, Verhoef VMJ, Arbyn M, Ogilvie G, Minozzi S, Banzi R, van Kemenade FJ, Heideman DAM, Meijer CJLM. High-risk HPV testing on selfsampled versus clinician-collected specimens: a review on the clinical accuracy and impact on population attendance in cervical cancer screening. Int J Cancer. 2013;132(10):2223-36.

19. Sultana F, English DR, Simpson JA, Drennan KT, Mullins R, Brotherton JML, Wrede CD, Heley S, Saville M, Gertig DM. Home-based HPV self-sampling improves participation by never-screened and under-screened women: results from a large randomized trial (iPap) in Australia. Int J Cancer. 2016; 139(2):281-90.

20. Enerly E, Bonde J, Schee K, Pedersen H, Lönnberg S, Nygård M. Selfsampling for human papillomavirus testing among non-attenders increases attendance to the Norwegian cervical Cancer screening Programme. PLoS One. 2016;11(4):e0151979.

21. Verdoodt F, Jentschke M, Hillemanns P, Racey CS, Snijders PJF, Arbyn M. Reaching women who do not participate in the regular cervical cancer screening programme by offering self-sampling kits: a systematic review and meta-analysis of randomised trials. Eur J Cancer. 2015;51(16):2375-85.

22. Farnsworth A. Self-sampling HPV testing versus mainstream cervical screening and HPV testing. Med J Aust. 2016;204(5):171.

23. Arbyn M, Castle PE. Offering self-sampling kits for HPV testing to reach women who do not attend in the regular cervical cancer screening program. Cancer Epidemiol Biomark Prev. 2015;24(5):769-72.

24. The Capital Region of Denmark is at the forefront of the fight against cervical cancer with an HPV home test. https://www.regionh.dk/english/ press-and-news/latest-news/Pages/The-Capital-Region-of-Denmark-is-at-theforefront-of-the-fight-against-cervical-cancer-with-an-HPV-home-test.aspx. Accessed 20 Mar 2017 
25. New Zealand Sexual Health Society. Sexually transmitted infections; summary of guidelines. Auckland: Sexually Transmitted Infection Education Foundation; 2015.

26. Rose SB, Lawton BA, Bromhead C, MacDonald EJ, Lund KA. Self-obtained vaginal swabs for PCR chlamydia testing: a practical alternative. Aust N Z J Obstet Gynaecol. 2007:47(5):415-8.

27. Arbyn M, Smith S, Temin S, Sultana F, Castle $P$, on behalf of the collaboration on self-sampling and HPV testing. Detecting cervical precancer and reaching underscreened women by using HPV testing on self-samples: updated meta-analyses. Brit Med J. 2018;363:k4823.

28. Arbyn M, Verdoodt F, Snijders P, Verhoef V, Suonio E, Dillner L, Minozzi S, Bellisario C, Banzi R, Zhao F-H, et al. Accuracy of human papillomavirus testing on self-collected versus clinician-collected samples: a meta-analysis. Lancet Oncol. 2014;15(2):172-83.

29. Stanczuk G, Baxter G, Currie H, Lawrence J, Cuschieri K, Wilson A, Arbyn M. Clinical validation of hrHPV testing on vaginal and urine self-samples in primary cervical screening (cross-sectional results from the papillomavirus Dumfries and Galloway-PaVDaG study). BMJ Open. 2016;6(4):e010660.

30. Bosgraaf RP, Verhoef VM, Massuger LF, Siebers AG, Bulten J, de Kuyper-de Ridder GM, Meijer CJ, Snijders PJ, Heideman DA. Comparative performance of novel self-sampling methods in detecting high-risk human papillomavirus in 30,130 women not attending cervical screening. Int J Cancer. 2015;136(3):646-55.

31. Sultana F, Gertig DM, Wredec CD, Englisha DR, Simpson JA, Drennanb KT, Brotherton JM, Phillips G, Heley F, Castleg PE, et al. A pilot study to compare dry cervical sample collection with standard practice of wet cervical samples for human papillomavirus testing. J Clin Virol. 2015;69:210-3.

32. Giorgi Rossi P, Marsili LM, Camilloni L, lossa A, Lattanzi A, Sani C, Di Pierro C, Grazzini G, Angeloni C, Capparucci P, et al. The effect of self-sampled HPV testing on participation to cervical cancer screening in Italy: a randomised controlled trial (ISRCTN96071600). Br J Cancer. 2011;104(2):248-54

33. Galbraith K, Gilkey M, Smith J, Richman A, Barclay L, Brewer N. Perceptions of mailed HPV self-testing among women at higher risk for cervical Cancer. J Community Health. 2014;39(5):849-56.

34. Racey C, Withrow D, Gesink D. Self-collected HPV testing improves participation in cervical Cancer screening: a systematic review and metaanalysis. Can J Public Health. 2013;104(2):e159-66.

35. Adcock A, Cram F, Lawton B, Geller S, Hibma M, Sykes P, MacDonald E, Dallas-Katoa W, Rendle B, Cornell T, et al. Acceptability of self-taken vaginal HPV sample for cervical screening among an under-screened indigenous population. Aust N Z J Obstet Gynaecol. 2019;59:1-7.

36. Brewer N, Foliaki S, Bromhead C, Viliamu-Amusia I, Pelefoti-Gibson L, Jones T, Pearce N, Potter J, Douwes J. Acceptability of human papillomavirus selfsampling for cervical-Cancer screening in under-screened Māori and Pasifika women: a pilot study. NZ Med J. 2019:132(1497):21-31.

37. National Screening Unit. Guidelines for cervical screening in New Zealand. Wellington: Ministry of Health; 2008

38. Ministry of Health. HISO 10001: 2017 ethnicity data protocols. Wellington: Ministry of Health; 2017.

39. Lim A, Sasieni P. Consultation rates in cervical screening non-attenders: opportunities to increase screening uptake in GP primary care. J Med Screen. 2015;22(2):93-9.

40. National Screening Unit. Change of timing for improvements to the National Cervical Screening Programme. https://www.nsu.govt.nz/news/ change-timing-improvements-national-cervical-screening-programme. Accessed 7 Mar 2019.

41. Cuzick J, Clavel C, Petry K-U, Meijer C, Hoyer H, Ratnam S, Szarewski A, Birembaut $P$, Kulasingam S, Sasieni $P$, et al. Overview of the European and north American studies on HPV testing in primary cervical cancer screening. Int J Cancer. 2006;119:1095-101.

42. Human papillomavirus (HPV) study. http://www.waitematadhb.govt.nz/ healthy-living/hpv-study/. Accessed 12 Sept 2019.

43. Martin G, Kaiwai H. For Wai research. Waitematā and Auckland District health board human papilloma virus cervical screening self-sampling (HPVSS) study in Māori women in West Auckland. In: Process and outcome evaluation. A report prepared for the Waitematā and Auckland District health boards. Wai Research: Auckland; 2017.

44. Sultana F, Mullins R, Murphy M, English DR, Simpson JA, Drennan KT, Heley S, Wrede CD, Brotherton JML, Saville M, et al. Women's views on human papillomavirus self-sampling: focus groups to assess acceptability, invitation letters and a test kit in the Australian setting. Sex Health. 2015;12(4):279-86.
45. Sultana F, Mullins R, English DR, Simpson JA, Drennan KT, Heley S, Wrede CD, Brotherton J, Saville M, Gertig DM. Women's experience with home-based selfsampling for human papillomavirus testing. BMC Cancer. 2015;15:849.

46. Ministry of Health. National Cervical Screening Programme Policies and standards: section 5: providing a laboratory service. Wellington: Ministry of Health; 2015.

47. Arbyn M, Snijders PJ, Meijer CJ, Berkhof J, Cuschieri K, Kocjan BJ, Poljak M. Which high-risk HPV assays fulfil criteria for use in primary cervical cancer screening? Clin Microbiol Infect. 2015;21(9):817-26.

48. Food US, Administration D. Approval letter for the cobas HPV test, Roche. US Food and Drug Administration: Silver Spring, MD; 2011.

49. Roche Molecular Systems Inc. The Netherlands is the first country to transition its national cervical cancer screening program from Pap to primary HPV screening. https://global.hpv16and18.com/hcp/netherlandshpv-primary-screening.html. Accessed 1 Sept 2016.

50. National Screening Unit. National Cervical Screening Programme: Changing the primary laboratory test. Public consultation submission summary. Wellington: Ministry of Health; 2016

51. Pearce N. Effect measures in prevalence studies. Environ Health Perspect. 2004:112:1047-50

\section{Publisher's Note}

Springer Nature remains neutral with regard to jurisdictional claims in published maps and institutional affiliations.
Ready to submit your research? Choose BMC and benefit from:

- fast, convenient online submission

- thorough peer review by experienced researchers in your field

- rapid publication on acceptance

- support for research data, including large and complex data types

- gold Open Access which fosters wider collaboration and increased citations

- maximum visibility for your research: over $100 \mathrm{M}$ website views per year

At $\mathrm{BMC}$, research is always in progress.

Learn more biomedcentral.com/submissions 